\title{
"Bin umgeknickt"
}

\section{Röntgen? Zwei Regeln geben's vor}

\begin{abstract}
Schätzungsweise bis zu 8000 Mal pro Tag werden in Deutschland Patienten mit Supinationsverletzungen des Sprunggelenks vorstellig. Wann geröntgt werden muss, dafür gibt es anerkannte und einfache Algorithmen.
\end{abstract}

Es handelt sich dabei um die Ottawa Ankle Rule und die Ottawa Foot Rule, erklären Dr. Hans Polzer von der Chirurgischen Klinik der LMU München und seine Kollegen. Nach der Ottawa Ankle Rule sind dann Röntgenaufnahmen des oberen Sprunggelenks in zwei Ebenen anzufertigen, wenn Schmerzen im Knöchelbereich bestehen und mindestens einer der folgenden Befunde vorliegt:

- Patient kann den Fuß unmittelbar nach dem Unfall und beim Arzt kei- ne vier Schritte belasten (dabei spielt es keine Rolle, wie er geht oder ob er humpelt)

- Druckschmerz über der Spitze der distalen Fibula und/oder über den distalen $6 \mathrm{~cm}$ der Fibula-Hinterkante

- Druckschmerz über der Spitze des medialen Malleolus und/oder über den distalen $6 \mathrm{~cm}$ der Tibia-Hinterkante.

Röntgenaufnahmen des Fußes in zwei Ebenen sind gemäß der Ottawa Foot Rule anzufertigen bei Fußschmerzen und wenn mindestens einer der folgenden Befunde vorliegt:

- Vier-Schritte-Regel wie oben

- Druckschmerz über der Basis des Os metatarsale V

- Druckschmerz über dem Os naviculare.
Gedacht werden muss selbstverständlich auch an eine hohe Fibula-Fraktur (Maisonneuve-Fraktur) wenn dort ein Druckschmerz vorliegt, müssen dementsprechende Untersuchungen folgen.

\section{$40 \%$ der Röntgenaufnahmen lassen sich vermeiden}

Hält man die Röntgenaufnahme für unnötig, müssen dem Patienten die Gründe dafür erläutert werden. Er sollte sich wieder vorstellen, wenn die Schmerzen innerhalb der nächsten fünf bis sieben Tage nicht nachlassen und er den Fuß nicht belasten kann. (TM) MMW Fortschr Med 2009, 151 (26-29): :48

\section{Infekt-Krimi Nr. 21}

\section{Dominikanisches Urlaubsfieber}

Vier Wochen lang war die 10-jährige Julia mit ihren Eltern in der Dominikanischen Republik. Sie hat im Meer gebadet und im Pool der Hotelanlage. Ausflüge ins Landesinnere haben sie und ihre Eltern nicht unternommen. Gegessen haben sie ausschließlich im Hotel. Alles in allem ein typischer Pauschalurlaub, bei dem die Familie auf eine Malariaprophylaxe verzichtete. Lediglich gegen Mückenstiche versuchten sie sich mit den üblichen Methoden zu schützen. Wieder daheim bekommt das sonst immer gesunde Mädchen Fieberschübe. Bis zu dreimal täglich steigt ihre Temperatur auf bis zu über $40^{\circ} \mathrm{C}$. Am Tag des Praxisbesuches eine Woche nach der Rückkehr hat sich Julia bereits zweimal erbrochen und klagt über Kopfschmerzen. Gegen DPaT, Polio, MMR, Hepatitis A und B, HIB und Salmonellen ist das Mädchen geimpft. Der Arzt diagnostiziert einen fieberhaften Infekt der Luftwege und macht einen Rachenabstrich. Da dieser unauffällig bleibt, konsultiert er einen Pädiater, der das Mädchen mit Verdacht auf Sepsis ins Krankenhaus einweist. Dort ergibt die initiale Laboruntersuchung normale Gerinnungsparameter, einen niedrigen Thrombozytenwert und einen erhöhten Leberwert. Auffällig sind zudem der Nachweis von Urobilinogen im Urin sowie freiem Hämoglobin im Plasma. Die Ärzte verlegen das Mädchen wegen einer akuten Hämolyse auf die Intensivstation. Ihr Allgemeinzustand bleibt schlecht. Julia hat weiterhin Fieber, geschwollene Lymphknoten, trockene Schleimhäute und einen leicht geröteten Rachen.

\section{$>$ Stimmt lhr Verdacht? Bitte umblättern:}

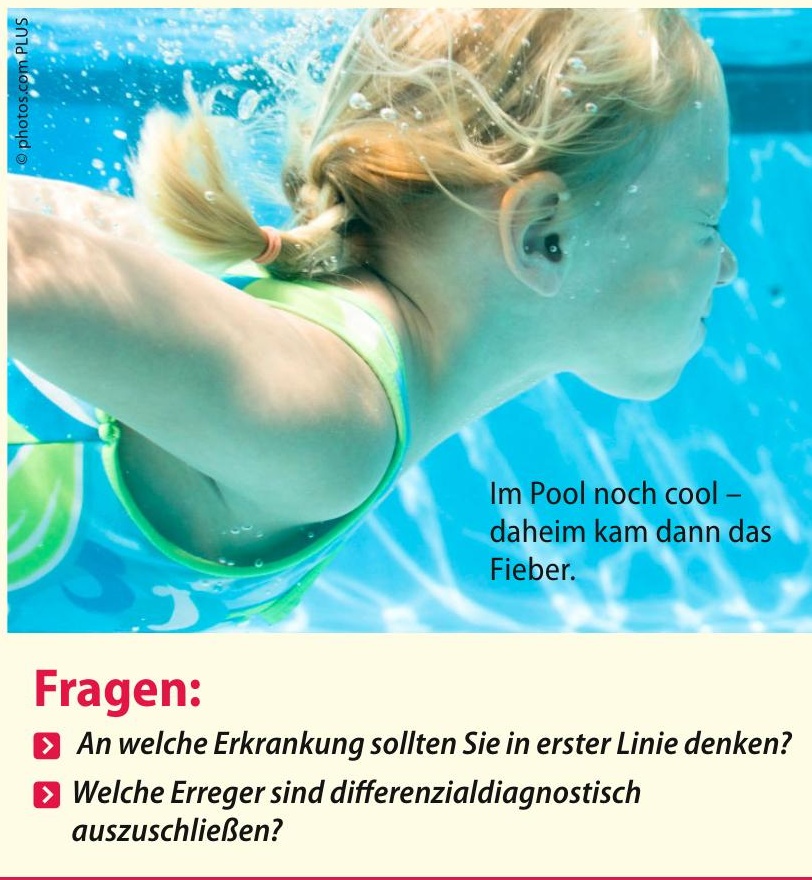

